\title{
Detrimental Effects of Variable Work Shifts on Quality of Sleep, General Health and Work Performance
}

\author{
Abdullahi Fido $^{a}$ Adel Ghali ${ }^{b}$ \\ ${ }^{a}$ Department of Psychiatry, Faculty of Medicine, Kuwait University, and b Kuwait Oil Company Hospital, Kuwait
}

\section{Key Words}

Insomnia, general health · Work performance •

Variable-shift work

\begin{abstract}
Objectives: The aim of this study was to explore the detrimental effects of working a varying pattern of 8-hour shifts on quality of sleep, general health and work performance. Subjects and Methods: The Arabic version of the Pittsburgh Sleep Quality Index (PSQI) and 2 self-administered questionnaires were used to assess quality of sleep, work performance and general health in a sample of 200 males on a schedule of varying 8-hour shifts at the Kuwait Oil Company. A matched sample of an equal number of workers on a fixed daytime shift as a control group was enrolled in the study. Results: Compared with men working on a straight daytime shift schedule, those working on 8-hour variable shifts exhibited higher rates of heavy smoking $(p<0.003)$, coffee/tea consumption ( $p<0.0001)$, constipation ( $p<$ $0.002)$, job stress $(p<0.0001)$ and poor sexual performance $(p<0.0001)$. Variable-shift workers reported persistent sleep disturbances in 3 dimensions of the global score of the PSQI $(p<0.0001)$. They also had significantly more complaints of fatigue $(p<0.005)$, poor level of work performance ( $p<$ $0.005)$ and loss of concentration $(p<0.005)$. Shift workers
\end{abstract}

were significantly more prone to making errors and having accidents at work, and were more likely to report absence from work than the controls $(p<0.0001$ and $p<0.005$, respectively). Conclusion: These results suggest that the majority of workers on an 8-hour variable-shift schedule experienced various health problems, poor quality of sleep and an increased risk for errors and accidents at work as compared with those workers on a straight daytime shift schedule. There is a need to compare potential benefits of an alternative work shift schedule. Copyright $\odot 2008$ S. Karger AG, Basel

\section{Introduction}

Sleep disturbances are among the most important health problems related to shift work [1]. These problems have been attributed to the requirement to work at times that are disruptive to shift workers' physiological, psychological and social circadian rhythms [2]. 'Sleep quality' is an important clinical construct for many health reasons. Poor sleep quality can be an important symptom of many sleep and medical disorders and might even have a direct association with mortality [3]. Field studies have indicated that people who work at night and on rotating shifts are at a high risk for involvement in accidents and

\section{KARGER}

Fax +4161306 1234 E-Mail karger@karger.ch www.karger.com (c) 2008 S. Karger AG, Basel

1011-7571/08/0176-0453\$24.50/0

Accessible online at: www.karger.com/mpp
Abdullahi Fido

Department of Psychiatry, Faculty of Medicine

Kuwait University, PO Box 24923

13110 Safat (Kuwait)

Tel. +965 533 0467, Fax +965 533 8904, E-Mail fido@hsc.edu.kw 
serious injuries on the job $[4,5]$. Another study reported higher rates of cigarette smoking and use of sleeping pills and alcohol among variable-shift workers [6]. Long-term exposure to variable shifts that include work at night is also associated with an increased risk for cancer, cardiovascular diseases, gastrointestinal illness and reproductive dysfunction in women $[7,8]$.

During the past 20 years, Kuwait has experienced enormous social and economic changes. It has developed into one of the world's major oil and financial centers. Rapid industrialization without environmental control could have resulted in major occupational health problems. While the negative impact of shift work on sleep and health has been extensively studied in western countries $[9,10]$, no study has assessed this relationship in the Arab world (except one in which reference was not made to health issues [11]). Therefore the objective of this study was to investigate the effects of a variable shift pattern on quality of sleep, work performance and general health.

\section{Subjects and Methods}

The sleep pattern and psychological profile of a sample of 200 male workers aged 24-50 years (mean 34.2, SD 7.3 years; study sample) on a variable schedule of 8 -hour shifts at the Kuwait Oil Company were studied over a 12-month period. Shift schedules comprised 35 days and were as follows: +AMMMM+++NNNNA $\mathrm{A}+++\mathrm{AAMMM}++++\mathrm{DNNNAA}+++$, where $\mathrm{N}=$ night $(22.00-$ $06.00 \mathrm{~h}), \mathrm{A}=$ afternoon (14.00-22.00 h), $\mathrm{M}=$ morning (06.00$14.00 \mathrm{~h}), \mathrm{D}=$ day and $+=$ free day. The AM and NA changes were 'quick changes', with only $8 \mathrm{~h}$ of rest in-between. The study sample was compared with a matched sample of 200 male workers aged 25-51 years (mean 34.5, SD 7.4 years; control sample) on a fixed daytime shift. Subjects in both samples were blue-collar workers with equal work experience, grades and work tasks. The Kuwait Oil Company is a major petrochemical industrial complex which employs about 3,000 people; $23 \%$ of the work force is involved in variable-shift work. The research protocol was approved by the Research Ethics Committee of Kuwait Oil Company Hospital. Written consent was obtained from all participants.

All individuals in both samples were subjected to full psychiatric screening by a consultant psychiatrist (A.F.) with respect to mental state, family and social situation, past psychiatric record and general medical status. Quality of sleep was measured by the validated Arabic translation [12] of the Pittsburgh Sleep Quality Index (PSQI) [13]. This self-rating instrument contained 19 questions. The 19 items were combined to form 7 component scores, each of which has a range of $0-3$ points. The 7 component scores were then added to yield one 'global' score with a range of $0-21$ points, with higher scores indicating 'worse' sleep quality. The 7 components of the PSQI were standardized versions of areas routinely assessed in clinical interviews of patients with sleep complaints. They were: (1) subjective sleep quality, (2) sleep latency, (3) sleep duration, (4) habitual sleep efficiency, (5) sleep distur- bances, (6) use of sleeping medications and (7) daytime dysfunction. A global PSQI score of more than 5 components yielded a diagnostic sensitivity of $89.6 \%$ and a specificity of $86.5 \%$ for the diagnosis of insomnia. In addition, all participants completed 2 further general health and work performance questionnaires. These were self-administered questionnaires which were adopted from an earlier similar study [14]. To establish face and content validity for the survey, an initial draft of the questionnaires was distributed to an experienced multidisciplinary team of health professionals working in the health sector. Their critical appraisal allowed revision for clarity and reliability. Each questionnaire contained 5 items that assessed general health and the level of work performance. For instance, the question about sexual performance was worded as: 'Have there been any changes in your sexual performance over the past 3 months?' Responses to each item were measured on a descriptive 3-step scale (descriptions such as 'increased', 'decreased' or 'no change' were used on the first questionnaire, and 'usual', 'sometimes' or 'none' were used on the second). Frequencies for each response were determined and subsequently computed into percentages. $\chi^{2}$ statistical tests were used to assess the association between 2 categorical variables. Student's t tests were used to compare the means of 2 continuous variables, and a one-way analysis of variance (ANOVA) was used for more than 2 groups. Statistical significance was set at $\mathrm{p} \leq 0.05$.

\section{Results}

The mean period of employment for both groups of workers was $12.9 \pm 4.9$ years. The variable-shift workers scored significantly $(\mathrm{p}<0.0001)$ higher than controls on both the global and component scales of the PSQI, including: subjective sleep quality; sleep latency; sleep duration, and daytime dysfunctions (fig. 1). Variable-shift workers did not significantly differ from controls in PSQI score for habitual sleep efficiency and in rates of use of sleeping pills. There were statistically significant differences between the 2 groups in the rate of heavy smoking $(\mathrm{p}<0.003)$, coffee/tea consumption $(\mathrm{p}<0.0001)$, constipation ( $\mathrm{p}<0.002)$, job stress $(\mathrm{p}<0.0001)$ and poor sexual performance $(\mathrm{p}<0.0001)$, as shown in table 1 . On average, variable-shift workers were significantly more likely to complain about loss of concentration ( $\mathrm{p}<0.005)$, poor work performance $(\mathrm{p}<0.0001)$ and fatigue $(\mathrm{p}<0.005)$ than fixed-shift workers. The variable-shift workers were also significantly more prone to errors and accidents at work and had a tendency to register more absence from work than did controls ( $\mathrm{p}<0.0001$ and $\mathrm{p}<0.005$, respectively) (table 2). 
Fig. 1. Comparison between the results obtained in the control group and the study group in PSQI (mean $\pm \mathrm{SD}$ ). ${ }^{*} \mathrm{p}<$ 0.0001 .

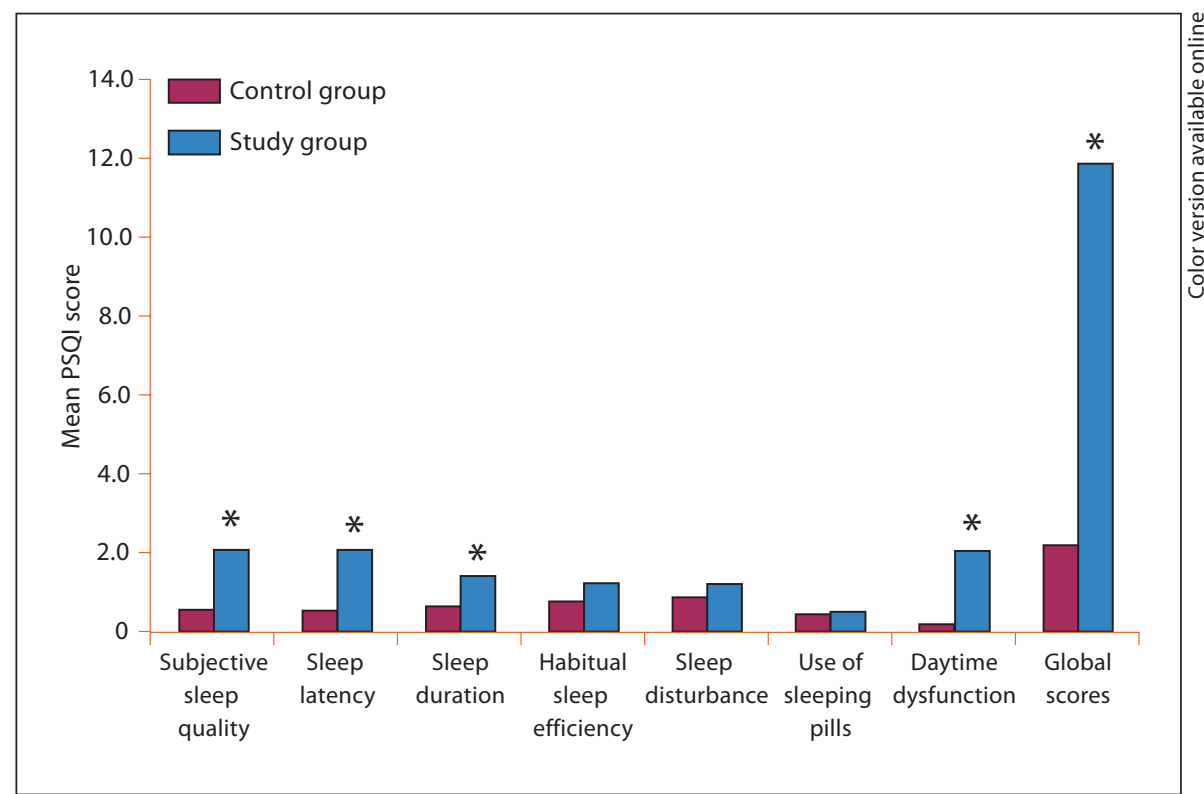

Table 1. Impact of variable-shift work duties on general health ( $n=200$ for both groups)

\begin{tabular}{|c|c|c|c|c|c|}
\hline & \multicolumn{2}{|c|}{$\begin{array}{l}\text { Fixed } \\
\text { (control) shift }\end{array}$} & \multicolumn{2}{|c|}{ Variable shift } & \multirow[t]{2}{*}{$\begin{array}{l}\mathrm{p} \\
\text { value }\end{array}$} \\
\hline & $\mathrm{n}$ & $\%$ & $\mathrm{n}$ & $\%$ & \\
\hline \multicolumn{6}{|l|}{ Smoking } \\
\hline Increased & 21 & 10.5 & 75 & 37.5 & \multirow{3}{*}{$<0.003$} \\
\hline Decreased & 8 & 4.0 & 4 & 2.0 & \\
\hline No change & 171 & 85.5 & 121 & 60.5 & \\
\hline \multicolumn{6}{|c|}{ Coffee/tea consumption } \\
\hline Increased & 15 & 7.5 & 101 & 50.5 & \multirow{3}{*}{$<0.0001$} \\
\hline Decreased & 6 & 3.0 & 20 & 10.0 & \\
\hline No change & 179 & 89.5 & 79 & 39.5 & \\
\hline \multicolumn{6}{|l|}{ Constipation } \\
\hline Usually & 15 & 7.5 & 83 & 41.5 & \multirow{3}{*}{$<0.002$} \\
\hline Sometimes & 30 & 15.0 & 106 & 53.0 & \\
\hline None & 155 & 77.5 & 11 & 5.5 & \\
\hline \multicolumn{6}{|l|}{ Stress } \\
\hline Usually & 29 & 14.5 & 145 & 72.5 & \multirow{3}{*}{$<0.0001$} \\
\hline Sometimes & 41 & 20.5 & 50 & 25.0 & \\
\hline None & 130 & 65.0 & 5 & 2.5 & \\
\hline \multicolumn{6}{|c|}{ Sexual performance } \\
\hline Increased & 19 & 9.5 & 4 & 2.0 & \multirow{3}{*}{$<0.0001$} \\
\hline Decreased & 11 & 5.5 & 69 & 34.5 & \\
\hline No change & 170 & 85.0 & 127 & 63.5 & \\
\hline
\end{tabular}

Table 2. Level of work performance among variable and fixed shift workers ( $\mathrm{n}=200$ for both groups)

\begin{tabular}{|c|c|c|c|c|c|}
\hline & \multicolumn{2}{|c|}{$\begin{array}{l}\text { Fixed } \\
\text { (control) shift }\end{array}$} & \multicolumn{2}{|c|}{ Variable shift } & \multirow[t]{2}{*}{$\begin{array}{l}\mathrm{p} \\
\text { value }\end{array}$} \\
\hline & $\mathrm{n}$ & $\%$ & $\mathrm{n}$ & $\%$ & \\
\hline \multicolumn{6}{|c|}{ Level of performance } \\
\hline Poor & 25 & 12.5 & 89 & 44.5 & \multirow{4}{*}{$<0.005$} \\
\hline Fair & 78 & 39.0 & 61 & 30.5 & \\
\hline Good & 57 & 28.5 & 28 & 14.0 & \\
\hline Excellent & 40 & 20.0 & 22 & 11.0 & \\
\hline \multicolumn{6}{|c|}{ Loss of concentration } \\
\hline Usually & 42 & 21.0 & 69 & 34.5 & \multirow{3}{*}{$<0.005$} \\
\hline Sometimes & 36 & 15.5 & 52 & 26.0 & \\
\hline None & 127 & 63.5 & 79 & 39.5 & \\
\hline \multicolumn{6}{|l|}{ Fatigue } \\
\hline Usually & 61 & 30.5 & 82 & 41.0 & \multirow{3}{*}{$<0.005$} \\
\hline Sometimes & 45 & 22.5 & 65 & 32.5 & \\
\hline None & 94 & 47.0 & 53 & 26.5 & \\
\hline \multicolumn{6}{|l|}{ Accidents at work } \\
\hline Two or more & 4 & 2.0 & 28 & 14 & \multirow{3}{*}{$<0.0001$} \\
\hline Once & 39 & 19.5 & 90 & 45 & \\
\hline None & 157 & 78.5 & 82 & 41 & \\
\hline $\begin{array}{l}\text { Days absent per } \\
\text { month }^{1}\end{array}$ & \multicolumn{2}{|c|}{$0.39 \pm 1.1$} & \multicolumn{2}{|c|}{$2.7 \pm 1.2$} & $<0.005$ \\
\hline
\end{tabular}




\section{Discussion}

The findings of this study show a persistently high rate of detrimental psychophysiological effects of stress related to working variable shifts, as previously reported [46]. The quality of sleep of the variable-shift workers differed significantly from that of the control group, both in global score and in many of its components, such as subjective sleep quality, sleep duration and daytime dysfunctions. Excessive cigarette smoking, coffee/tea consumption, gastrointestinal disorders, work stress and sexual dissatisfaction occurred more frequently among variable-shift workers than daytime fixed-shift workers. Almost half of the variable-shift workers were dissatisfied with their work performance and exhibited significantly more mental stress and fatigue, and less ability to concentrate. The 'healthy worker' effect does not seem to adequately explain the differences between the 2 groups.

It has been reported that shift work gives rise to various neurophysiological disorders due to disturbance in circadian rhythms [15]. In our study, variable-shift workers in general experienced a greater sense of distress, depression and fatigue. They described themselves as being habitually more tired during the day and less refreshed on awakening. It has been suggested that the basic mechanism causing these disturbances could be related to the circadian misalignment of sleep during the day, when the circadian drive for wakefulness is high [16].

It was also argued that, due to the increased sleep pressure from prior sleep loss during shift work, a compensatory reduction in the sleep latency of daytime sleep may have taken place. This, in turn, would reduce the need to spend time in bed, thereby mitigating the reduction in sleep efficiency [17]. On the other hand, Parkes [18] has reported that under common conditions, a shift worker's subjective experience of sleep quality may be related to his/her personality characteristics rather than the biology of sleep and circadian rhythm.
Strategies have been developed to enhance circadian adaptation to shift work schedules. Factors that promote sleep hygiene are advised, such as adequate sleep, sleep in a quiet and dark environment, control of the use of caffeine and alcohol, and timing sleep to the desired sleep time relative to shift schedule. Exposure to light can phase-shift circadian rhythms, therefore scheduled exposure to bright light and avoidance of light (possibly by use of dark goggles) might be useful in accelerating adaptation [19]. There is, however, strong evidence [20] that the circadian cycle can adjust more completely to a continuous or slowly rotating shift pattern than it can to the 8-hour variable-shift schedule studied here.

This study has a few obvious limitations. It is possible that aspects of an individual personality might either relate to selection onto an unfavorable shift schedule or influence reporting of work characteristics in a negative manner. In addition, this study is cross-sectional and, consequently, is thought to be confounded by self-selection effects, known as the 'healthy worker' effects. A better way to look at the association between a variable-shift schedule and risk of developing sleep disorders would be to examine those who had experienced either an adverse or a beneficial change prior to variable-shift work compared with those whose work had stayed the same. This type of analysis may be less susceptible to response bias. Although these findings rely on self-reported data, all attempts were made to control for the most confounding factors, except for the personality variable.

\section{Conclusions}

The results presented in this study would suggest that variable-shift workers, in general, showed a higher level of psychopathology related to sleep disturbances resulting from 8-hour shift work as compared to those workers on a straight daytime shift.

\section{References}

Akerstedt T: Shift work and disturbed sleep/ wakefulness. Occup Med 2003;53:89-94.

$\checkmark 2$ Monk TH: What can the chronobiologist do to help the shift worker? J Biol Rhythms 2000;15:86-94.

-3 Akerstedt T, Fredlund P, Gillberg M, Jansson B: A prospective study of fatal occupational accidents - relationship to sleeping difficulties and occupational factors. J Sleep Res 2002;11:69-71.

\footnotetext{
4 Smith L, Folkard S, Poole CJ: Increased injuries on night shift. Lancet 1994;344:11371139.

5 Smith R, Kushida C: Risk of fatal occupational injury by time of day. Sleep 2000;23: $110-111$.

6 6 Lieberman HR, Tharion WJ, Shukitt-Hale B: Effects of caffeine, sleep loss, and stress on cognitive performance and mood during US Navy SEAL training. Psychopharmacology 2002;164:250-261.
} 
7 Boggild H, Knutsson A: Shift work, risk factors and cardiovascular disease. Scand J Work Environ Health 1999;25:85-99.

$>8$ Hakola T, Harma MI, Laitinen JT: Circadian adjustment of men and women to night work. Scand J Work Environ Health 1996; 22:133-138.

-9 Van der Hulst: Long work hours and health. Scand J Work Environ Health 2003;29:171188.

$>10$ Balkin P, Bliese G, Belenky H: Comparative utility of instruments for monitoring sleepiness related decrements in the operational environment. Sleep 2004;13:219-227.

11 Attia M: Optimization of night and shift work plans among policemen in Kuwait. A field Experiment. Int Occup Environ Health 1985;5:81-90.
12 Gundy T: The use of the Arabic validated version of the PSQI for the measurement of quality of sleep of patients with schizophrenia. Egypt J Psychiatry 1996;88:167-185.

13 Buysee D, Reynolds CF 3rd, Monk TH, Berman SR, Kupfer DJ: The Pittsburgh Sleep Quality Index: a new instrument for psychiatric practice and research. Psychiatr Res 1989;28:193-213.

14 Mifter B, Kipchoke S: The use of self-reported instrument measuring health-related work productivity. East Afr J Psychiatry 1988;6:61-70.

15 Saber C, Lu J, Chou T: The hypothalamic integrator for circadian rhythms. Trends Neurosci 2005;28:152-157.
16 Monk T: Shift work; in Kryge M, Roth T (eds): Principles and Practice of Sleep Medicine. Philadelphia, Elsevier-Saunders, 2005, pp 673-679.

17 Kerkhof G, Lancel M: EEG slow wave activity, REM and rectal temperature during night and day in morning-type and eveningtype subjects. Psychophysiology 1991;28: 678-688.

18 Parkes KR: Sleep patterns, shiftwork and individual differences: a comparison of onshore and offshore control-room operators. Ergonomics 1994;37:827-844.

19 Bolvin D, James F: Light treatment and circadian adaptation to shift work. Ind Health 2005;43:34-48.

$>20$ Beers T: Flexible schedules and shift work: replacing the '9-to-5' workday? Mon Labor Rev 2000;123:33-40. 